\title{
Artistic Transformation of Used Products
}

\author{
Chengyuan Ren \\ Tianjin Polytechnic University \\ Tianjin, China
}

\author{
Huiqing Guo \\ Tianjin Polytechnic University \\ Tianjin, China
}

\author{
Yuting Mei \\ Tianjin Polytechnic University \\ Tianjin, China
}

\begin{abstract}
Design is a way to make people have a better life, and now with the people's awareness of environmental protection, we have given more and more attention to the environment, waste disposal in the environment is often a difficult problem to solve. In our lives there will always be some waste items, such as old furniture, old toys, old cartons, old bottles and old clothes, when you want to throw away these waste items, and it will be a pity, after all, these things used for a long time, already with their own feelings. How to give them "a second life", so that they continue to play a new role? The transformation of used products is a good way. It can not only help us to reuse waste items again, but also show an environmentally friendly and healthy way of life. So based on the principle"make the best use of everything" , perhaps through your transformation, these old things will become completely different things present in front of you, and no longer being used as garbage. The theme of this paper is designed to integrate into the transformation of used products, including the design of waste products. To enhance people's understanding of the transformation of waste materials, and enhance people's attention to waste design.
\end{abstract}

Keywords—reorganization; art transformation; environmental protection; recycling

\section{INTRODUCTION}

The current energy conservation and environmental protection is a key area of global concern,the sustainable design of products will naturally become the focus of the study. In general, the current trend in product design is the development and production of new products, but the production of second-hand reuse products is very rare. Therefore, the theme of this paper for the transformation of used products, in the transformation, we can add the art of the ingredients into the waste products, for the waste have a new life. The following will combine some cases, specifically to introduce some of the old products recycling cases.

\section{RECYCLING OF USED PRODUCTS}

\section{A. Method of Transformation of Waste Product Function}

Recycling of used product features refers to the use of old product functions, such as furniture in the seat, such as sofas, chairs, cabinets, etc., sofa and seat for us to provide a rest function, the cabinet is What we offer is the function of placing items. After the transformation of these used furniture, let it continue to play the original function. Everyone's home will have some old furniture, these furniture materials are generally used in the wood. Used furniture may not be perfect, but there are often bright spots, and sometimes even incomplete is a kind of beauty, to see what kind of design language we use to interpret. Some elements of the old furniture has a unique visual tension, the designer can give its new artistic charm, so that its original value can be greatly improved

Belt Furniture-Dutch designer Piet Hein Eek created a collection of small wooden mosaic furniture, world-renowned Waste Waste $40 \times 40$ series "Fig. 1", the entire series are 40 $\times 40 \mathrm{~mm}$ waste Wood cutting cube-are scraped from the waste wood furniture waste, and then cut together carefully made together to create a new work.

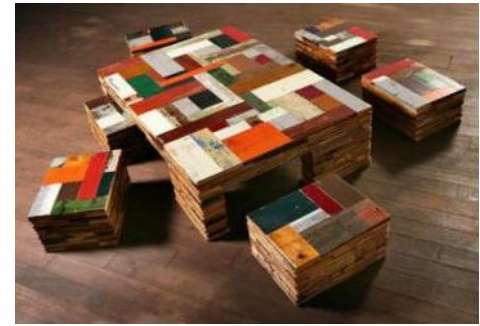

Fig. 1. Waste Waste $40 \times 40$ series wood furniture.

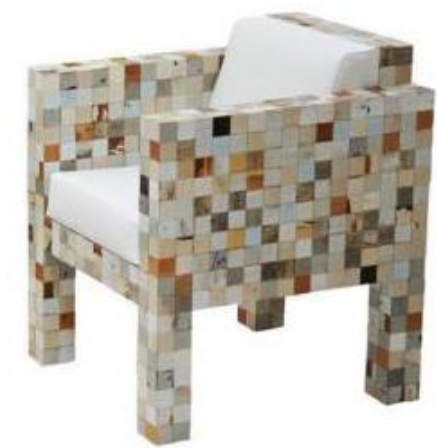

Fig. 2. King Of Upcycling series wood furniture.

And his other series KING OF UPCYCLING "Fig. 2"-Piet Hein Eek. Giving the impression that it is eclectic, cool and difficult to resist the idea, from the hut-style home office, Door 
Project and even for the artist Guido Geeleen to create a streamlined brass / glass display box, his works also extended to include Recycled wood furniture, pottery, splint series, aluminum products and special mixed material works. Piet Hein Eek is widely recognized and favored in the upsurge of today's renewable raw material design.

\section{B. Rebuilding Method of Intensive Transformation Method of Recycling of Used Product}

Transformation of intensive products refers to the full use of all resources on the basis of more centralized and rational use of some technology, the full reorganization of some small items in the form of the reorganization of waste products, both decorative, but also both functional Sex.

The home of the light bulb is broken, do not rush to throw it away, to collect up, you just add creative fun design, a little hands, it can become a useful thing in our lives. To the time of the festival to decorate and then appropriate. "Fig. 3"

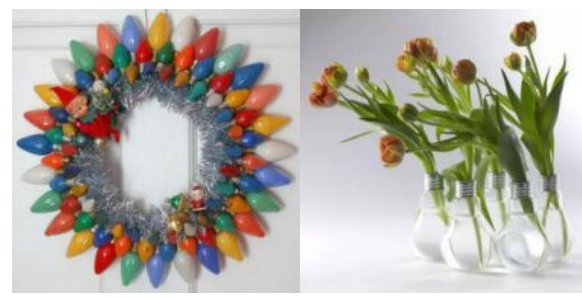

Fig. 3. Example of Christmas decorations( light bulb).

This Sunday newspaper (chair / stool "Fig. 4"), which was designed by designer David Stowell using a tight-knit Sunday newspaper. By connecting the hand-rolled newspaper and the polypropylene belt material together. The product encourages people to turn their attention to materials, especially those in the eyes of the waste, and re-valuation of these waste, looking for new ways to use them, rather than discard them. Of course, we still have a lot of ways to make an artistic transformation of the old book.

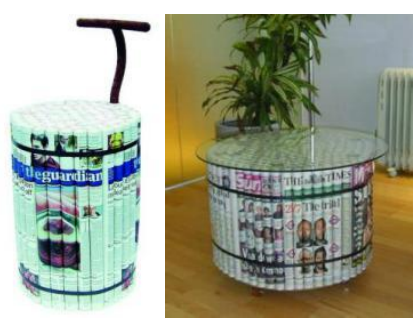

Fig. 4. Sunday newspaper table and chair.

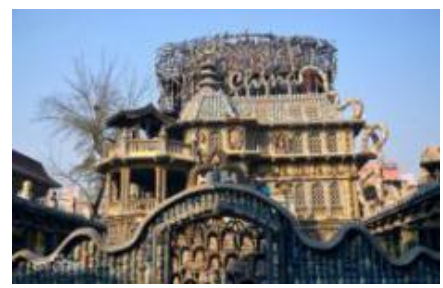

Fig. 5. Tianjin porcelain house.

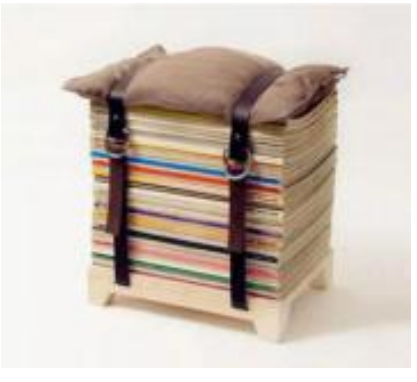

Fig. 6. Old books and old magazines Stool.

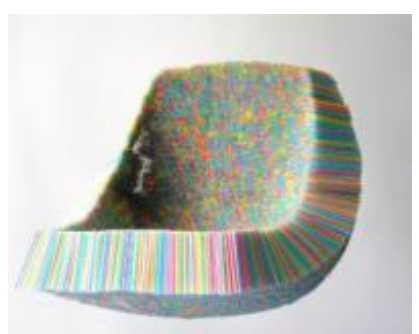

Fig. 7. Plastic straws chair.

\section{Method of Recycling of Used Products}

Split restructuring is the transformation of the waste products after cutting, separation, break up, select the part of the waste products, and then use a certain tool for the part of the waste products for adhesion, sewing, reorganization. Speaking of the typical case of split and reorganization, it would have to mention the porcelain house in Tianjin, China. This "porcelain house" "Fig. 5" is a Chifeng Road, Tianjin, with a number of antique decoration made of French-style. The exterior and interior of the porcelain house makes full use of the debris of the old porcelain, mixed with concrete and pasted on the outside. The fragments of these porcelain are from different times. The building is known as: a priceless "Chinese ancient porcelain museum". Porcelain house meaning, not just a collection of works of art collection, more importantly, it contains the Chinese cultural symbols. Porcelain house will show the essence of Chinese culture to the world, so that more people understand the Chinese culture, explore the history of China.

Let's look at a case of "old book stool" "Fig. 6". You can not think of home old books and old magazines if the transformation, it will help you save a lot of expenses! A small stool at home, bedside cabinets can be obtained by stacking old books of different heights. Simple to you can not believe. Such as with the waste belt on the book bundled to achieve the height you want, both environmental protection and literature at the same time, but also to have a certain functionality.

One-time straw colorful colors, the most suitable for artistic transformation, disposable straw finally have the new value of environmental protection! British designer Scott Jarvie designed Clutch seat and the shape of the lamp makes people clapped. As the chef without the seasoning, the dishes in the design Clutch seat, Scott Jarvie by the trees in the structure for the transport of nutrients and moisture capillary inspired by thousands of plastic straws together to create a shape as shown in the figure Showing a gem-shaped shape "Fig. 7". Whether to 
use them as a lamp or a chair, to see your personal preferences. Designers dare to boldly use new materials, the design will have a rich "expression."

"Old skateboard tables and chairs",Skateboard play can be converted into tables and chairs, remove the wheels of the skateboard as solid and durable, and graffiti shape also makes tables and chairs more unique. "Fig. 8"

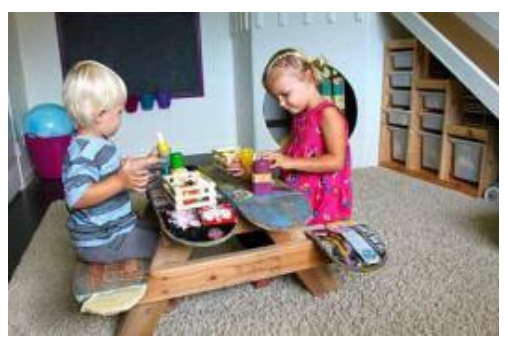

Fig. 8. Old skateboard tables and chairs.

There will always be some old sweater inside the home, throw away the pity, we can cut the old sweater, plus buttons, play creative, made their own style. Such as can be made into an interesting size backpack,comfortable pillow "Fig. 9", both stylish and exclusive feeling. Can also be made into red wine packaging "Fig. 10", to reduce the chance of being broken.

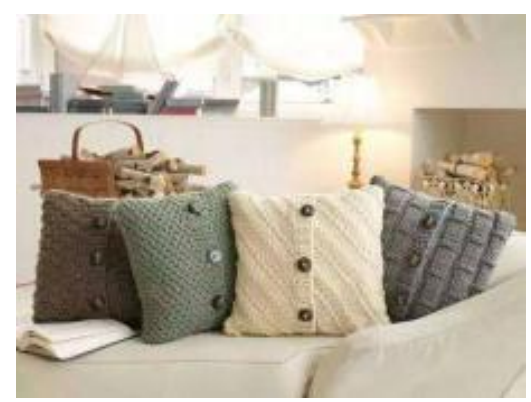

Fig. 9. Old sweater pillow.

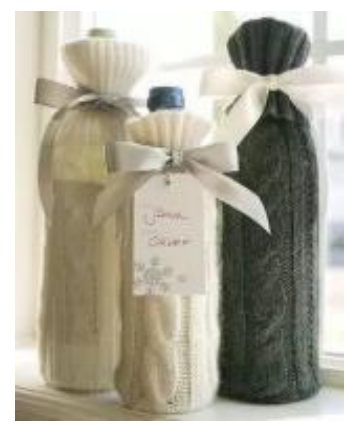

Fig. 10. Old sweater red wine packaging.

In the interior design, some old clothes can be used as pillow, gloves "Fig. 11" to design, so that their own furniture has a mysterious retro feelings. Truly split the reorganization, so that every piece of waste can be used as a reusable material.

\section{Decorative Furnishings Function Transformation and Reconstruction Method}

Decorative furnishings are suitable for most of the used products, because the old objects, although not a cultural relic, but on behalf of an era, the background of the times, it is the master of life fragments of each one may be hidden behind a beautiful The old objects, such as the Shanghai watch, the red light, the old furniture, and so on, always make a lot of memories, these old objects have been sublimated into a work of art, these old objects as a design can often evoke a lot of people clear And resonance, because these old objects in people's minds have left a deep impression, the contrast will be impressive.
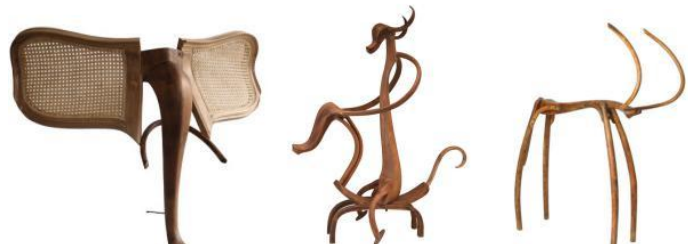

Fig. 11. Wood carvings form French artist marc sparfel.

Many old furniture was abandoned because it was no longer fashionable or had no use value. However, in the hands of the French artist marc sparfel, these outdated old chairs, wardrobes and coat racks become urban forests grown from the asphalt road, climbing the city lights and walls. The artist sparfel was deeply attracted by these abandoned furniture, and he personally picked the best of them and brought them back to the studio for reworking. This process is slow and painful, but the artist has always been intuitive design, in order to find the original form of wood furniture in the new elegance and poetic. "Fig. 11"

Focus on the transformation of old objects to give artistic language, the transformation of old things only the use of value or not enough, but also contains some unique significance, which is a sense of design. Good design in addition to the function, there must be connotation, to integrate into their own connotation of the idea, the connotation of art design far more than the art itself, so as to transform the valuable and taste of the works. We in the transformation of the old things to pay attention to the story behind the elements of things, a can attract eyeball works, must not itself, but its connotation. The transformation of old things can be elements of the event through the contradictions, to give the old sense of transformation of meaning, to show the transformation of the old material regeneration. In the moment, the old transformation is not intended to face the environmental pollution and the rational use of resources in a good way, in the face of increasingly serious environmental problems today, our home is also piled a pile of discarded life supplies, Childhood favorite toys, is not still worried about the home is very strange, in fact, we do not have to worry about these, to play our imagination and creativity to transform them to let the blood of art re-flow into their body so that they have a new New value of life. In this era, for the product designer, the biggest test is to think about the existence of a necessity. Whether it is rich or poor countries, are faced with the problem of excess products, how to produce the right products, not for the earth to bring too heavy burden, really worth pondering. 


\section{WASTE MATERIAL TRANSFORMATION PRACTICE}

Through these simple design let us fully feel the real meaning of the best use of the meaning. Modern society is an economic society, but also a large number of waste of resources, excessive packaging is also our ecology suffered heavy losses, pollution of limited water resources, but also a threat to soil safety. Therefore, how to re-use, to become an important topic to be discussed now, in addition to reducing waste, and the harmless treatment of waste, is how these have been produced out of the greatest degree of waste re-design,

So that these designs into the daily life, so that the public to develop "the best use of art" habits, so that waste design as part of daily life. Perhaps a few years later will be out of the old public toilets, old bars, old restaurant, old hotel, and even the old museum and a large number of waste transformation of large works ... believe that waste recycling will become a new industry, it Will nourish our lives and nourish the earth that we live on.

In the daily life, there will always be some bottles and jars, these bottles can be used for the second use, such as mineral water bottles, milk bottles, beverage bottles, etc., so the practice of waste transformation, to these bottles as transformation of the object, the final selection of trapped winding transformation design transformation. So that these bottles and jars are both beautiful and functional, such as vases, pen holder, bookshelves and so on.

First of all, we can according to their own preferences to choose the old sweater at home, the old sweater dismantling into a line, in accordance with the law wrapped in the outside of the bottle, and then select some of the old buttons or clothes lace, as the bottle of the edge, A variety of containers, in line with a home of the comfortable state. "Fig.12"

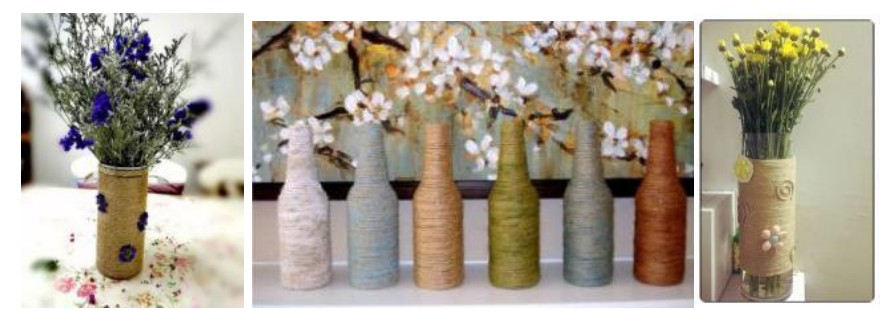

Fig. 12. Example of Practice case.

\section{CONCLUSION}

By analyzing the above several cases of recycling of used products, we can see that as long as we are willing to spend time for life, we can make use of waste products to make more interesting life supplies, to facilitate our lives. In life, everyone can become a designer, for their own housing to add some fun, but also for the Earth's environment to do some contribution. For the transformation of old objects covered with the design of the coat, you can make these waste products become better works of art, so that more people feel "old things to bring a better life experience."

\section{REFERENCES}

[1] Tingting. Design is a kind of life to make a good power - global environmental design case tracking [J]. China Advertising, 2013, (07): 76-80.

[2] Danya, on behalf of. Old things transfiguration [J]. Modern decoration (home), 2011, (08): 136-139

[3] Li Xinhao. Reconstruction of old objects - regeneration in interior design [J]. Modern Decoration (Theory), 2015, (11): 16.

[4] Li Heng. Based on the green design of the old re-use [D]. Xinjiang Normal University, 2015. 